\title{
Diplopia developed by cervical traction after cervical spine surgery
}

\author{
Ji-Yoon Kim ${ }^{1}$, Hyuna Kim ${ }^{2}$, So Jeong Kang ${ }^{3}$, Hyunjee Kim ${ }^{4}$, Young-Seok Lee ${ }^{5}$
}

${ }^{1}$ Department of Anesthesiology and Pain Medicine, School of Medicine, Kyungpook National University, Kyungpook National University Chilgok Hospital, Daegu, Korea

${ }^{2}$ Department of Ophthalmology, Gyeongsang National University Hospital, Gyeongsang National University College of Medicine, Jinju, Korea ${ }^{3}$ Department of Anesthesiology and Pain Medicine, Kyungpook National University Hospital, Daegu, Korea

${ }^{4}$ Department of Anesthesiology and Pain Medicine, School of Medicine, Kyungpook National University, Kyungpook National University Hospital, Daegu, Korea

${ }^{5}$ Department of Neurosurgery, School of Medicine, Kyungpook National University, Kyungpook National University Chilgok Hospital, Daegu, Korea

Received: April 1, 2020

Revised: July 10, 2020

Accepted: July 11, 2020

Corresponding author:

Young-Seok Lee, MD, PhD

Department of Neurosurgery,

School of Medicine, Kyungpook

National University, Kyungpook

National University Chilgok

Hospital, 807 Hoguk-ro, Buk-gu,

Daegu 41404, Korea

Tel: +82-53-420-5647

Fax: +82-53-422-9195

E-mail: leeys1026@hanmail.net
Diplopia is a rare complication of spine surgery. The abducens nerve is one of the cranial nerves most commonly related to diplopia caused by traction injury. We report a case of a 71-year-old woman who presented with diplopia developing from abducens nerve palsy after C1-C2 fixation and fusion due to atlantoaxial subluxation with cord compression. As soon as we discovered the symptoms, we suspected excessive traction by the instrument and subsequently performed reoperation. Subsequently, the patient's symptoms improved. In other reported cases we reviewed, most were transient. However, we thought that our rapid response also helped the patient's fast recovery in this case. The mechanisms by which postoperative diplopia develops vary and, thus, remain unclear. We should pay attention to the fact that the condition is sometimes an indicator of an underlying, life-threatening condition. Therefore, all patients with postoperative diplopia should undergo thorough ophthalmological and neurological evaluations as well as careful observation by a multidisciplinary team.

Keywords: Abducens nerve; Cranial nerve diseases; Diplopia; Spinal fusion

\section{Introduction}

Perioperative ocular complications are rare yet important. The American Society of Anesthesiologists (ASA) Closed Claims database was initiated in 1984 to analyze anesthesia malpractice and improve patient safety. Data from the ASA Closed Claims have shown that intraoperative eye injuries account for $4 \%$ of medico-legal claims, indicating that eye care is an important part of anesthesia-related care [1]. Diplopia can rarely present after spine surgery. As a result, there have been a few investigations on this condition, and the mechanism by which diplopia develops follow- ing spine surgery remains unknown [2]. The current report summarizes the current literature and presents a case of postoperative diplopia that developed following cervical spine surgery. We hope that this report will lead to a better understanding of postoperative diplopia and how best to manage patients with the condition.

\section{Case}

This study was approved by the Institutional Review Board (IRB) of Gyeongsang National University Hospital (IRB No: 2018-09016). Written informed consent was obtained from the patient for

Copyright (C) 2021 Yeungnam University College of Medicine

This is an Open Access article distributed under the terms of the Creative Commons Attribution Non-Commercial License (http://creativecommons.org/licenses/by-nc/4.0/) which permits unrestricted non-commercial use, distribution, and reproduction in any medium, provided the original work is properly cited. 
publication of this case report and accompanying images.

A 71-year-old woman (height, $149 \mathrm{~cm}$; weight, $62 \mathrm{~kg}$ ) was admitted in the outpatient department. The patient complained of pain and tightness on the side of her neck and an accompanying tingling sensation in both hands that had been ongoing for 3 years. The patient had a 20-year history of hypertension and was taking hypertensive drugs (olmesartan medoxomil, $20 \mathrm{mg}$; hydrochlorothiazide, $12.5 \mathrm{mg}$; and cilnidipine, $10 \mathrm{mg}$ ). She was diagnosed with atlantoaxial subluxation with cord compression and was treated with a $\mathrm{C} 1-\mathrm{C} 2$ fixation and fusion (Fig. 1A, 1B). The surgical time was 170 minutes and the total anesthesia time was 265 minutes. The patient had perioperative bleeding with an estimated blood loss of $300 \mathrm{~mL}$. As a result, the patient received 1 unit of packed red blood cells intraoperatively, which led to hemodynamic stability. Following surgery, the patient was transferred to a general ward for recovery. One day after surgery, the woman complained of acute horizontal diplopia. Ophthalmologic examination revealed limited lateral gaze $(-0.5)$ in the left eye and esotropia (2 prism diopters $[\mathrm{PDs}])$ in the left eye in primary gaze position with distant fixation, which increased to 5 PDs in left gaze position. Based on these findings, the patient was suspected to have left abducens nerve palsy. Her best corrected visual acuity was 20/25 (plano; Dcyl -2.00, axis $\left.90^{\circ}\right)$ in the right eye and $20 / 20(\mathrm{Dsph}+1.25$, Dcyl -2.25 , axis $90^{\circ}$ ) in the left eye. Anterior segment findings and pupillary reflex were normal in both eyes. No abnormal finding was observed in the eyelid. Neurologic examination including brain magnetic resonance imaging did not provide any specific finding except diplopia. The surmised cause of diplopia was thought to be associated with excessive 6th cranial nerve $(\mathrm{CN})$ due to $\mathrm{C} 1-\mathrm{C} 2$ fixation and fusion. In preoperative cervical spine plain radiography, Powers ratio was 0.80 (Fig. 1A). After the C1-C2 fixation of fusion, Powers ratio was increased to 1.04 (Fig. 1B). We judged this to be an excessive rod distraction. Therefore, rod repositioning was performed to reduce the interspinous distance. After reoperation, Powers ratio decreased to 0.87 (Fig. 1C). However, there was no change in the atlanto-dental interval during perioperative period (Fig. 1). Two days after cervical spine surgery ( 1 day after nerve traction reduction), the patient reported an improvement in symptoms. Thirty-five days after the initial surgery ( 34 days after nerve traction reduction), diplopia had resolved completely.

\section{Discussion}

Diplopia is a rare complication after spine surgery, but several cases have been reported [2-9]. In non-spine surgery, diplopia has been reported mainly in patients undergoing spinal anesthesia, and only rarely in patients undergoing general anesthesia [10]. In the case presented here, the patient did not complain of postoperative diplopia immediately after spine surgery or during anesthetic recovery. Other reports have described times of onset of diplopia varying from 1 day to several days after operation (Table 1) [2-9]. As a result of its delayed onset, postoperative diplopia is rarely diagnosed by the anesthesiologist. It is very difficult to explain the mechanisms associated with delayed onset of diplopia after spine surgery. We presume that the following factors may contribute to delayed onset of diplopia. Intraoperative dural tear, spinal anesthe-
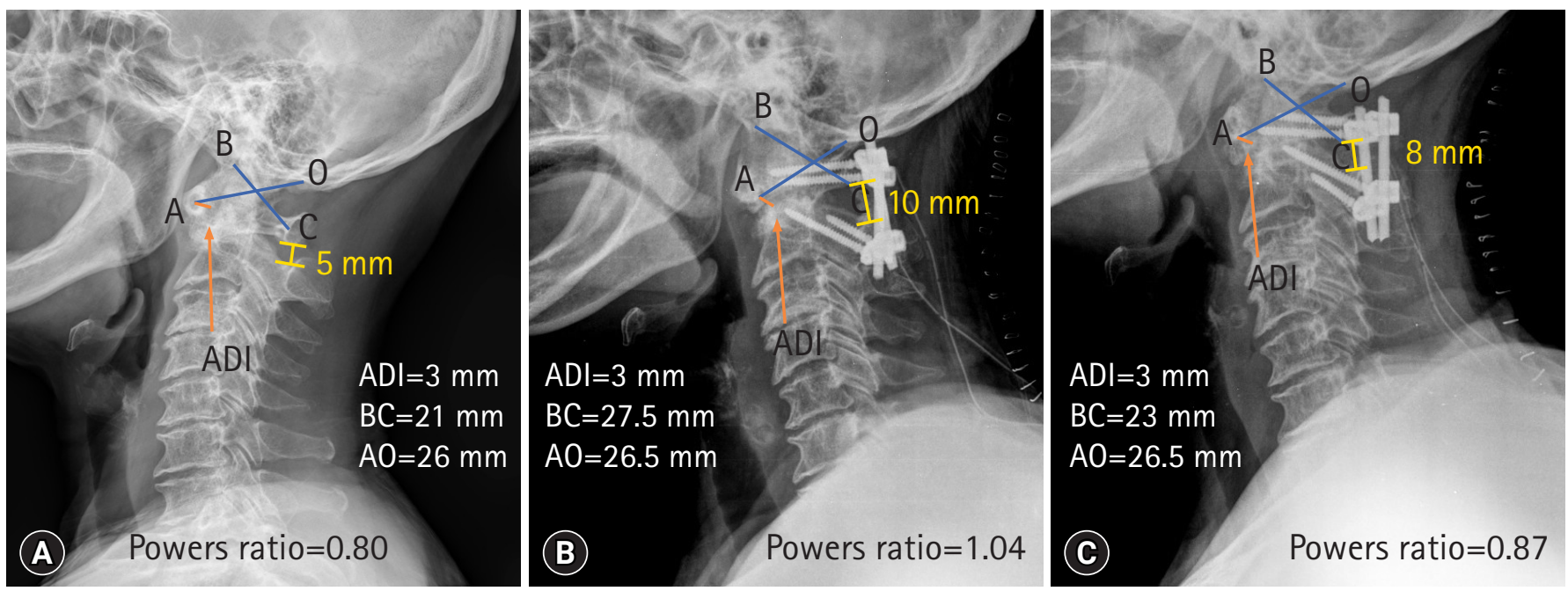

Fig. 1. Pre- and postoperative cervical spine lateral plain radiography. (A) Preoperative, (B) 1st postoperative, and (C) after 2nd postoperative images. $\mathrm{ADI}$, atlanto-dens interval; $\mathrm{BC}$, distance from the basion to the anterior aspect of the posterior arch of $\mathrm{C} 1 ; \mathrm{AO}$, distance from the posterior aspect of the anterior arch of $\mathrm{C} 1$ to the opisthion; Powers ratio, $\mathrm{BC} / \mathrm{AO}$. In cases of Powers ratio $>1$ in plain radiographs and $\mathrm{ADI}>3 \mathrm{~mm}$, anterior atlanto-occipital dissociation should be suspected. 
Table 1. Reported cases of diplopia after spine surgery

\begin{tabular}{|c|c|c|c|c|c|c|c|c|c|c|}
\hline Year & Author & Surgery & $\begin{array}{l}\text { Patient } \\
\text { sex }\end{array}$ & $\begin{array}{l}\text { Age } \\
\text { (yr) }\end{array}$ & $\begin{array}{l}\text { Surgical } \\
\text { position }\end{array}$ & Spine level & $\begin{array}{l}\text { Presumed } \\
\text { causes of } \\
\text { diplopia }\end{array}$ & $\begin{array}{l}\text { Palsy detection } \\
\text { (postoperative } \\
\text { day) }\end{array}$ & Treatment & $\begin{array}{l}\text { Palsy } \\
\text { remission }\end{array}$ \\
\hline 1999 & Barsoum et al. [9] & Laminectomy & Male & 59 & Prone & Lumbar & Traction & Unknown & Conservative & 6 Months \\
\hline 2003 & Nakagawa et al. [6] & $\begin{array}{l}\text { Spinal tumor } \\
\text { resection }\end{array}$ & Female & 22 & Prone & Cervical & CSF leakage & 3 & Conservative & 1 Year \\
\hline 2009 & Cho et al. [3] & Posterior fusion & Male & 61 & Prone & Lumbo-sacral & CSF leakage & 2 & Conservative & 5 Weeks \\
\hline \multirow[t]{4}{*}{2011} & Abd-Elsayed et al. [2] & Fusion & Female & 14 & Prone & Lumbar & Facial edema & 1 & Conservative & Few days \\
\hline & & Fusion & Female & 34 & Prone & Lumbar & Facial edema & 1 & Conservative & 5 Days \\
\hline & & Fusion, discectomy & Female & 67 & Supine & Cervical & Facial edema & 1 & Conservative & Few days \\
\hline & & Fusion & Female & 18 & Lateral & Thoraco-lumbar & Facial edema & 1 & Conservative & 3 Days \\
\hline 2012 & Thomas et al. [8] & Discectomy & Male & 53 & Prone & Lumbar & CSF leakage & 7 & Dural repair & 2 Weeks \\
\hline 2013 & Joo et al. [4] & Discectomy & Male & 48 & Prone & Lumbo-sacral & CSF leakage & 3 & Dural repair & 1 Week \\
\hline \multirow[t]{2}{*}{2013} & Khurana et al. [5] & Discectomy & Male & 48 & Prone & Thoracic & CSF leakage & $>21$ & $\begin{array}{l}\text { Dural } \\
\text { repair+chest } \\
\text { drain }\end{array}$ & 3 Months \\
\hline & & Discectomy & Male & 46 & Prone & Thoracic & CSF leakage & Unknown & Conservative & 5 Months \\
\hline 2016 & Sandon et al. [7] & Discectomy & Female & 47 & Prone & Thoracic & CSF leakage & 10 & $\begin{array}{l}\text { Dural } \\
\text { repair+chest } \\
\text { drain }\end{array}$ & 1 Month \\
\hline 2020 & This report & Fusion & Female & 71 & Prone & Cervical & Traction & 1 & Conservative & 35 Days \\
\hline
\end{tabular}

CSF, cerebrospinal fluid.

sia, and primary intracranial hypotension produce cerebrospinal fluid (CSF) leakage, leading to traction of brain with stretching of CNs, such as the abducens nerve, resulting in subsequent diplopia $[4-9,11]$. Since most patients are usually in the lying position following the operation, the CSF leakage is relatively smaller compared with that in the sitting position; hence, diplopia is relieved [11]. However, when the patient sits or stands a few days after operation, the diplopia worsens due to relatively more CSF leakage compared with that in the lying position [4-8,11]. In addition, during the immediate postoperative period, non-attention by the surgeon, depending on the severity of diplopia, may also contribute to delayed onset of diplopia.

The mechanisms by which diplopia develops are diverse and not well understood, but $\mathrm{CN}$ injury is a well-known and obvious cause $[2,9]$. Extraocular muscles that control eye movement are innervated by $\mathrm{CNs}$, including the oculomotor nerve (CN3), trochlear nerve (CN4), and abducens nerve (CN6) [12,13]. Diplopia occurs due to a malfunction of the extraocular muscles and/or the nervous system components that control them [12,13]. Of all the CNs, CN6 is thin and has a long intracranial course $[14,15]$. It emerges from the ventral aspect of the brainstem at the pontomedullary junction and runs through Dorello's canal between the dura and skull (Fig. 2) $[12,13]$. After piercing the dura, the nerve turns sharply forward at the tip of the petrous temporal bone to enter the cavernous sinus (Fig. 2) [12,13]. In the cavernous sinus, CN6 runs laterally to the internal carotid artery and medial to CN3, CN4, and CN5 (the trigeminal nerve) (Fig. 2) [12]. This sudden intra- cranial spatial alteration and compression of Dorello's canal are the main causes of CN6 injury $[12,13]$. Also, atherosclerosis and dolichoectasia of vessels can compress the nerve [13]. After continuing forward, CN6 finally leaves the cavernous sinus and enters the orbit through the superior orbital fissure (Fig. 2) [12,13]. At this point, it is encircled by a common tendinous ring. CN6 then innervates the lateral rectus muscle and produces eye abduction (Fig. 2) $[12,13]$. This long pathway makes CN6 particularly vulnerable to mechanical damage caused by bones and ligaments. Indeed, this was observed in our case, in which diplopia occurred due to excessive traction of the 6 th $\mathrm{CN}$. We identified the change in the atlanto-occipital area presented as an increase in Powers ratio after C1C2 fixation and fusion with the occurrence of diplopia. Diplopia improved with normalization of the Powers ratio after the second surgery. Based on these features, the changes in the atlanto-occipital area after $\mathrm{C} 1-\mathrm{C} 2$ fixation and fusion may be associated with CN6 traction injury as the cause of diplopia. Previously, CN paralysis or damage was reported to occur due to the use of equipment such as Gardner-Wells tongs, halo traction, or halo-pelvic traction [9]. Other nerves, including the glossopharyngeal nerve (CN9), the vagus nerve ( $\mathrm{CN} 10)$, and the hypoglossal nerve ( $\mathrm{CN1}$ ), are most vulnerable to stretching injury because of their vertical or oblique course through the cranium. However, the most commonly injured nerve is CN6, with most cases caused by trauma and perioperative traction [2,13-16]. In addition, CSF leakage, CSF hygroma, face edema and traction, and wrong head position on the head rest may cause diplopia following spine surgery [2-9,17]. Fur- 


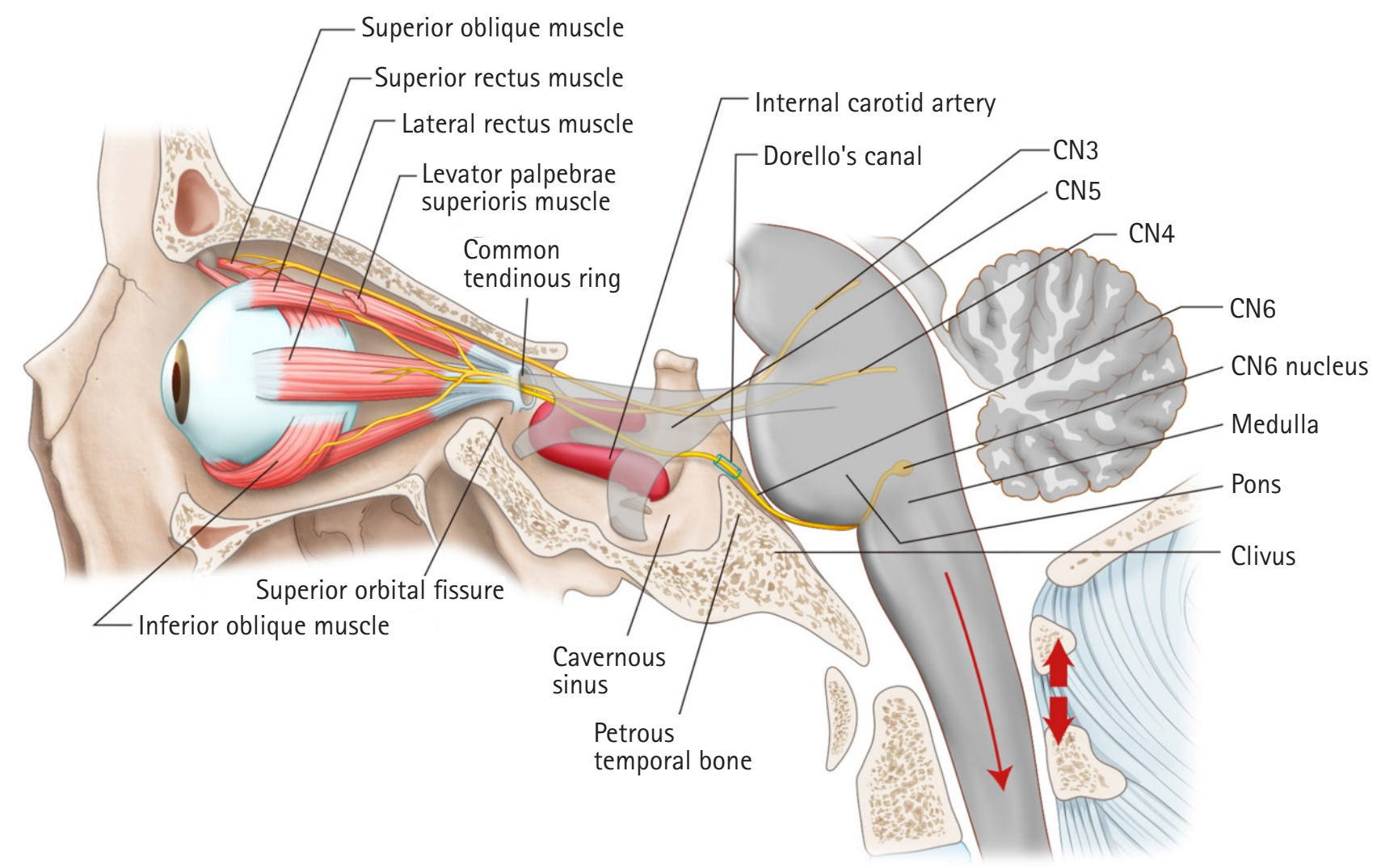

Fig. 2. Anatomy and mechanism by which CN6 palsy develops. The CN6 has a very long intracranial course, making this nerve particularly vulnerable to damage. Operative traction, hyperextension (thick arrows), and downward brain placement (thin arrow) can result in stretch injuries where the abducens nerve enters Dorello's canal. CN3, oculomotor nerve; CN4, trochlear nerve; CN5, trigeminal nerve; CN6 abducens nerve.

thermore, diplopia following spine surgery may indicate a life-threatening situation, which can be associated with subdural hematoma and transtentorial herniation [18]. Therefore, it is recommended to manage patients with diplopia following spine surgery with immediate ophthalmology and neurology consultations. If no pertinent issues are identified, occlusion therapy with patching or prism glasses is the first line of treatment. If there is no improvement after this non-surgical treatment, corrective eye surgery or a botulinum toxin injection into the lateral rectus muscle can be attempted [7]. However, these more invasive therapies are usually not needed, and conservative treatment improves diplopia because most patients spontaneously improve over time (Table 1) [2$9,15]$.

In conclusion, diplopia is a rare complication of spine surgery that can be caused by perioperative traction, CSF leakage, and facial edema and traction. Fortunately, these patients generally have a good prognosis because other neurologic complications such as perioperative visual loss generally do not occur, and most patients tend to make a full recovery. However, diplopia does require immediate ophthalmological examination, neurological evaluation, and careful observation because it may be a sign of a life-threatening condition, including subdural hematoma.

\section{Acknowledgments}

\section{Conflicts of interest}

No potential conflict of interest relevant to this article was reported.

\section{Author contributions}

Conceptualization: JYK; Data curation: SJK, HK, YSL; Investigation and Visualization: SJK, HK; Validation: YSL; Writing-original draft: JYK, HK; Writing-review \& editing: HK, JYK, YSL.

\section{ORCID}

Ji-Yoon Kim, https://orcid.org/0000-0001-7998-8936

Hyuna Kim, https://orcid.org/0000-0002-6127-2187

So Jeong Kang, https://orcid.org/0000-0002-6448-7124

Hyunjee Kim, https://orcid.org/0000-0002-6336-7622

Young-Seok Lee, https://orcid.org/0000-0002-6881-812X 


\section{References}

1. Metzner J, Posner KL, Lam MS, Domino KB. Closed claims' analysis. Best Pract Res Clin Anaesthesiol 2011;25:263-76.

2. Abd-Elsayed AA, Barsoum W, Bell G, Farag E. Diplopia following spine surgery: a case series. Open Neurosurg J 2011;4:14-5.

3. Cho DC, Jung ES, Chi YC. Abducens nerve palsy after lumbar spinal fusion surgery with inadvertent dural tearing. J Korean Neurosurg Soc 2009;46:581-3.

4. Joo JD, Yoon SH, Kim KJ, Jahng TA, Kim HJ. Isolated abducens nerve palsy due to cerebrospinal fluid leakage following lumbar discectomy: a rare clinical entity. Eur Spine J 2013;22(Suppl 3):S421-3.

5. Khurana A, Brousil J, Russo A, Evans A, Quraishi NA, Boszczyk $B M$. Intracranial hypotension with a sixth cranial nerve palsy subsequent to massive thoracic CSF hygroma: a rare complication of thoracic disc excision. Eur Spine J 2013;22:2047-54.

6. Nakagawa H, Kamimura M, Uchiyama S, Takahara K, Itsubo T, Miyasaka T. Abducens nerve palsy as a rare complication of spinal surgery: a case report. J Orthop Sci 2003;8:869-71.

7. Sandon LH, Choi G, Park E, Lee HC. Abducens nerve palsy as a postoperative complication of minimally invasive thoracic spine surgery: a case report. BMC Surg 2016;16:47.

8. Thomas A, Shetty AP, Rajasekaran S. Abducens nerve palsy associated with pseudomeningocele after lumbar disc surgery: a case report. Spine (Phila Pa 1976) 2012;37:E511-3.

9. Barsoum WK, Mayerson J, Bell GR. Cranial nerve palsy as a complication of operative traction. Spine (Phila Pa 1976)
1999;24:585-6.

10. Althomali AT. Diplopia after general anesthesia a post-operative complication or mere coincidence? case report. J Eye Cataract Surg 2016;2:11.

11. Schievink WI. Spontaneous spinal cerebrospinal fluid leaks and intracranial hypotension. JAMA 2006;295:2286-96.

12. Blumenfeld $H$. Neuroanatomy through clinical cases. 2 nd ed. Sunderland (MA): Sinauer Associates; 2010. p. 566-70.

13. Miller NR, Subramanian PS, Patel VR, Walsh FB, Hoyt WF. Walsh \& Hoyt's clinical neuro-ophthalmology: the essentials. 3rd ed. Philadelphia (PA): Lippincott Williams \& Wilkins; 2016. p.365-7.

14. Romero FR, Ramos JG, Chaddad-Neto F, Bethencourt JM, de Oliveira E. Microsurgical anatomy and injuries of the abducens nerve. Arq Neuropsiquiatr 2009;67:96-101.

15. Dengler BA, Bartanusz V. Bilateral abducens nerve palsy following ligamentous C1-C2 distraction. Eur Spine J 2014;23(Suppl 2):248-52.

16. Master CL, Scheiman M, Gallaway M, Goodman A, Robinson RL, Master SR, et al. Vision diagnoses are common after concussion in adolescents. Clin Pediatr (Phila) 2016;55:260-7.

17. Kumar N, Jivan S, Topping N, Morrell AJ. Blindness and rectus muscle damage following spinal surgery. Am J Ophthalmol 2004;138:889-91.

18. Hassen GW, Kalantari H. Diplopia from subacute bilateral subdural hematoma after spinal anesthesia. West J Emerg Med 2012;13:108-10. 